\title{
Metaphors in Mentalization-Based Treatment: Reintroducing the Language of Change in "Plain Old Therapy"
}

\author{
E. J. Folmo ${ }^{1}$ (1) T. Langjord ${ }^{2,3} \cdot$ N. C. S. Myhrvold ${ }^{4} \cdot$ M. Lind $^{5}$
}

Accepted: 10 June 2021 / Published online: 23 June 2021

(c) The Author(s) 2021

\begin{abstract}
Metaphors, a central conduit of change in psychotherapy, have not been taken adequately into account in MentalizationBased Treatment (MBT). Despite successfully utilized by other evidence-based treatments for borderline personality disorder (BPD), MBT considers metaphors confusing for patients with low mentalizing abilities. For metaphors and teaching stories to stimulate growth within the window of tolerance, interventions should be responsively tailored (e.g., explained). Metaphors might be a route to making spoken matter more apprehensible, and bridge emotions with cognitive content. They hold the potential for challenging without being too confronting, and to translate knowledge between different range of understanding. This theoretical article presents why the use of metaphors in MBT—in the hands of a responsive therapists—may prove a powerful tool to open social trust, despite being considered a "high risk" intervention. The timeless lens of the metaphor may help us connect with archetypical versions of our own narratives, hence understanding our subjectivity in a larger perspective. By reaching towards concepts beyond our normal reasoning, typically denoted perennial philosophy or wisdom, they may substitute and/or supplement mentors in a memorable way.
\end{abstract}

Keywords Mentalization-based treatment (MBT) · Metaphor · Wisdom stories · Borderline personality disorder (BPD) · Pedagogic stance $\cdot$ Narrative identity

\section{Introduction}

The avoidance of metaphors in Mentalization-based treatment (MBT) is intriguing. Metaphors can translate understanding from one arena to another, and is characterized by many as the language of change. Muran and Digiuseppe

$\triangle$ E. J. Folmo

espfol@ous-hf.no

1 Norwegian National Advisory Unit On Personality Psychiatry, Division of Mental Health \& Addiction, Section for Personality Psychiatry \& Specialized Treatments, Oslo University Hospital, Ullevaal, PO Box 4956, 0424 Oslo, Nydalen, Norway

2 Division of Mental Health \& Addiction, Section for Personality Psychiatry \& Specialized Treatments, Department for National and Regional Functions, Oslo University Hospital, Oslo, Norway

3 Department of Psychology, University of Oslo, Oslo, Norway

4 Tunsberg Medical School, Tønsberg, Norway

5 Department of Psychology, University of Florida, Gainesville, FL, USA
(1990) argues that metaphors is a method of teaching and communicating across several fields. As people are naturally inclined to think metaphorically, the clinical use and management of metaphors have long interested therapists, with Arlow claiming that "psychotherapy is an inherently metaphoric enterprise" (Tay, 2013, p. 3). MBT, sometimes denoted "plain old therapy" (POT; Allen, 2012), is developed on the basis of traditional psychoanalysis, as well as research on attachment and social cognition for treating Borderline Personality Disorder (Bateman \& Fonagy, 2016; Karterud et al., 2020). The theory and work of Lakoff and Johnson (2008) underline the metaphorical embedding in our minds and linguistical day-to-day practice, language, and thus alludes to its helpfulness in psychotherapy.

Well-performed MBT has been reported to challenge the patients' comfort zone (Folmo et al., 2019). In line with such a carefrontational style, metaphors seem to be a useful tool to (1) challenge patients, (2) avoid direct confrontation, (3) make unconscious patterns conscious, and (4) teach or translate concepts from one arena to another (Muran \& Digiuseppe, 1990), and according to our view also across time and place (e.g., epoch and culture). The current article 
intends to investigate the role of metaphors and teaching stories as a potential way to strengthen and negotiate the alliance in MBT. This article takes on a theoretical approach, as the MBT manual (Bateman \& Fonagy, 2016) advises against the use of metaphors and teaching stories. Such a theoretical approach seems appropriate as metaphors and teaching stories can communicate "timeless truths" from early philosophers to contemporary authors, including cruxes leading to human change: "there exist certain 'timeless truths,' consisting of common observations of how people change. These observations date back to early philosophers and are reflected in great works of literature" Goldfried (1980, p. 996). This article will first outline why the use of metaphors and teaching stories can be beneficial in MBT. Next, we will elaborate on when metaphors and teaching stories can be successfully implemented in MBT and how to overcome the commonly mentioned obstacles in using metaphors in MBT.

\section{Why Metaphors Matter in MBT}

Our ordinary conceptual system, in terms of which we both think and act, is fundamentally metaphorical in nature. These concepts govern our thought, our everyday functioning, but also structure what we perceive, how we get around in the world, and how we relate to other people (Lakoff \& Johnson, 2008). The hypothesis of linguistic relativity posits that the language, or the logos, we operate within is a large contributor to how we view our reality (Bohnemeyer, 2020). As expressed by Kopp (1995): "Metaphors are mirrors that reflect our inner images of self, life, and others. Like Alice, we can go through the looking glass and journey beyond the mirror's image, entering the domain of creative imagination wherein metaphoric imagery can become a key that unlocks new possibilities for self-created 'in-sight' and therapeutic change" (Kopp, 1995, pp. xiii-xiv). The parables of the Bible, the teachings of Kabbalah, the koans of Zen Buddhism, the allegories of literature, the images of poetry, modern TV series, movies, and the myths and fairy tales of storytellers, all make use of metaphors to transport knowledge on the epistemic highway (accelerated sociocultural trust). Metaphors can be (1) conventional, i.e., part of our language to such an extent that we hardly recognize them as metaphors; and (2) creative, i.e., coining new words and meanings from different semantic areas. The focus in this article is on the creative variant, where fresh meaning and imagery are created from different conceptual or cognitive areas. With the frame of cognitive linguistics (Croft \& Cruse, 2004), metaphors can be described as letting concretely pictured physical objects and situations stand in for the more abstract objects and situations the therapist and the patient are endeavoring to understand. Thus, metaphors might be a route to making spoken matter more apprehensible. In the therapeutic room, possible misunderstandings (due to metaphors) can be checked and nuanced immediately, thus further ameliorating the use of metaphors in (MBT) treatment.

The therapeutic use of metaphors typically involves abstracting or translating a concept from a topic that the client knows well into another, with the aim of explaining or constructing an experience in a different arena (e.g., Muran \& Digiuseppe, 1990). In terms of finding appropriate metaphors, the rules for use in cognitive therapy are as follows: (a) identify the concept that you wish to communicate or teach; (b) attend to the client's language and search for an arena which he/she understands or display mastery; (c) search for an analogue construct in the client's arena of knowledge that includes the core elements of the concept that you wish to teach; and (d) if none exists or comes to mind, start over with a new arena about which the client has knowledge (Muran \& Digiuseppe, 1990, p. 79).

However, in MBT, "the clinician is less attentive on the use of metaphor, analogies and symbolism drawn from the content and instead focuses on developing an increasingly robust mentalizing process" (Bateman \& Fonagy, 2016, p. 208). The main reasoning for advising against metaphors in MBT is that they "require a high level of mentalizing and are likely to be beneficial in furthering understanding only at those moments when the person with BPD is able to balance internal emotional states with inner reflection. At other times such interventions will be met with either incomprehension, envious admiration, dismissal, or development of pretend mode" (Bateman \& Fonagy, 2016, p. 208). However, metaphor is central in several BPD treatments, and we will next indicate how such an intervention is informed by theories found at core of MBT.

\section{Metaphor as Ostensive Cue}

Recently, Luyten et al. (2020b) have redefined BPD as a disorder of social communication resulting in marked impairments in the "sense of self-coherence and self-continuity because the individual is unable to benefit from the organizing influence of social communication and social recalibration of the mind" (p. 91). Hence, the role of social learning (epistemic trust) has been proposed as the core of BPD and is considered a central component ensuring the effectiveness of BPD treatment (Luyten et al., 2020b; Sharp et al., 2020). Fonagy and his colleagues (2015) have redefined the term "epistemic" from Aristotle (epistémé; Schwartz, 2011) to denote the trust necessary for social communication. When the epistemic highway is opened, it allows accurate and flexible mentalizing to unfold (Luyten et al., 2020b). Ostensive cues are social signals we provide to attain epistemic trust, such as paying close attention, demonstrating both an ability for complex understanding, and a willingness to confront maladaptive patterns. As we seem evolved to learn 
from stories, and shared narratives, we find it interesting to assume that the use of metaphor is indeed an ostensive cue-a potent key to epistemic trust.

\section{Proposed Principles for Metaphors in MBT}

\section{Why the Use of Metaphors and Teaching Stories can be Beneficial in MBT?}

As it is suggested that our conceptual system is largely metaphorical (Lakoff \& Johnson, 2008), bringing this to awareness through MBT treatment may be inherently valuable. Metaphors-which are also at core of shared intentionality (Tomasello, 2010) - may be one way to bridge old and new knowledge and mint new ways of relating to self and others. In short, metaphors and (teaching) stories allow for accelerated communication, and may foster therapeutic alliance through the ostensive cue of appreciative attentiveness.

\section{When to Use Metaphors and Teaching Stories Successfully in MBT?}

The "use of metaphor may be indicated if the client (or the therapist) finds it difficult to understand why they feel the way they do about something" (Hackmann et al., 2011, p. 152), e.g., as this may change the perspective and lead to insight about their felt state. As mentalizing unites mental and emotional awareness (Luyten et al., 2020a), it is likely that mentalizing of metaphors could be a way to bring simultaneous awareness to both realms. If the emotions become difficult to inhabit, allow, or describe, it can be easier to pinpoint them by recalling familiar situations where the patient can recognize the same sensation. In such situations, where the therapist has detected the need for a bridge between thoughts and emotions (e.g., the patient feels the emotions, but is unable to verbalize them), the therapist might point or confirm or validate, by using a metaphor. This will function as a language pointer, be an enzyme for recognition, and confirm the normality of the content. Personalized metaphors could serve the purpose of exemplifying how well the therapist sees the patient and provide the feeling of being recognized deeply (e.g., empathic attunement; Kohut, 1984).

\section{How to Overcome the Commonly Mentioned Obstacles in Using Metaphors in MBT?}

Aristotle warns of the ambiguity and obscurity inherent in metaphors (McKeon, 2009); as there are many ways that a metaphor can be taken, the possibility of mistakes abounds. Hence, one reason why metaphors should be implemented with care in BPD treatments is that they may highjack the epistemic highway, and cause misunderstandings. To avoid pretend mode, a state where the patient disconnects emotionally from the explored content (a major concern when introducing metaphors in BPD treatments), the client should be encouraged to explore the metaphorical image experientially in addition to talking about it (Hackmann et al., 2011). Further, to avoid incomprehension and dismissal, it seems helpful to make the mental image as clear and concrete as possible: In art therapy, as part of MBT, metaphors are used creatively in mapping one representation on to another, producing new perspectives, as in portraying a landscape onto the person as an image of his or her journey through life (Havsteen-Franklin, 2019). Such a map can also be helpful for therapists, and can both capture narratives the patient holds at core, or central narratives about change: Metaphors seem part of the MBT case formulations, which “can be related to Stern's concept of a 'key metaphor,' representing core relational and emotional themes" (Bateman \& Fonagy, 2019, p. 257). Such metaphors concerning the therapeutic process itself may be of particular importance (Tay, 2020). In DBT, "at the very start of skills training, the opportunity arises to enter the paradox of how it can be that everyone is doing the best they can and simultaneously everyone needs to do better" (Linehan, 2014, p. 84). Presenting patients with such a healing myth (or core concepts in the model) is at the core of social healing (Wampold \& Imel, 2015). Though, the use of metaphors in psychotherapy should also include informing the patient of the rationale for doing so and ensure that it is related to the therapeutic setting.

The guidelines for use of metaphors in MBT could be inspired by the practices of other evidence-based treatments for BPD. The DBT manual simply states that the "most common dialectical strategies in DBT are storytelling and metaphors" (Linehan, 2014, p. 84). In Transference-Focused Psychotherapy (TFP), another evidence-based treatment for BPD, a "metaphor selected from the patient's own language often can serve as a particularly vivid, succinct, and emotionally rich way for patient and therapist to talk about complex self and object images" (Clarkin et al., 1999, p. 64). If the therapist says you "acted as if you had the right to be a child who is not responsible for her actions, where the mother has the responsibility of picking up after her child regardless" (Clarkin et al., 1999, p. 65), it would illustrate the use of metaphor in characterizing the active part-self and part-object representations. The manual for TFP (Clarkin et al., 1999) advises that the "therapist should enter this process of naming roles as the presentation of a hypothesis to be tested and refined on the basis of the patient's response, not as truth to be accepted. The therapist should attend carefully to the patient's manifest agreement or disagreement as implied by the subsequent associations. If the therapist recognizes that he or she was incorrect, or even somewhat missed the mark, he or she should feel free to acknowledge this and provide a revised impression" (p. 65). 
Picture a patient who claims that "Nobody cares about me!" The therapist could easily address this by making a simple case of putting a number from 0 to 10 on how much different people they know care about them. Such tools provide an alternative framework through which thoughts can operate, and this is the very essence of therapy according to MBT theory. Let us say a patient struggles with severe anxiety or depression. A metaphoric formulation is one way of elucidating and wording the struggle. Imagine you're in a tug of war with some huge anxiety, or depression-monster. You hold on to one end of the rope, and the monster has the other end. In between you, there is a huge bottomless pit. You are pulling backward as hard as you can, but the monster keeps pulling you ever closer to the pit. What is the best thing to do in this situation? Pulling harder comes naturally, but the harder you pull, the harder the monster pulls. You are stuck. What do you need to do? Dropping the rope means the monster is still there, but you are no longer tied up in a struggle with it. Now you can do something more useful.

Using such a metaphor for changing maladaptive patterns, and in a condensed manner convey certain psychopedagogic themes, could involve inviting the individual to investigate what the rope could represent, what the pit contains, which muscles resist, or what listening to the monster would mean. In doing so, the therapist provides a common drawing table (mental image), where they can practice mentalization. Both by dissecting the present situation and the ideas that would emerge in the process. To avoid painful pitfalls, patients may be asked to restate the metaphor introduced by the therapist in their own words, after which they should try to adjust or replace it, if possible. The (MBT) therapist may also directly question the patient's "understanding of the metaphor, and how it relates to desired behavior and emotional well-being, and on the range of situations where they see it as applicable."

\section{Internalized Mentors}

Identity disturbance has long been considered one of the defining features of BPD (Leichsenring et al., 2011), and the development of agency through the reconstruction of personal life stories may be a crucial mechanism in psychotherapy with BPD patients (Lind et al., 2019). The metaphor of being in a tug of war with a monster could serve as a personalized structuring of a mental struggle, and a following resolve within the narrative might lead to a greater sense of agency - through illustrating and adapting a hard to grasp mental struggle to a concrete 'monster' or figure, the patient might find his or her own strategies of meeting and resolving complex troubles. This could disentangle the pain, by providing a different framework through which thoughts can operate. The stories we tell ourselves, how we tell them, and how we understand them are a central part of our identity and our wisdom (Glück \& Bluck, 2013). There are several ways by which someone's narratives could be disconnected from "evidence"-while "positive proof may enhance our confidence in a proposition, not every confidently held proposition needs to have been systematically proven" (Kruglanski, 2013, p. 24). The use of metaphors and teaching stories has three advantages above normal reasoning: (a) within normal reasoning, patients may forget why they concluded as they did (once a given proposition was accepted as true, a person may forget its evidential basis); (b) many assumptions are not derived from evidence, but rather from strong intuitions, or other inferences; and (c) patients may lack the capability to come up with alternatives to a given belief, e.g., unable to imagine that things could be other than what they presently seem. In terms of wis$\mathrm{dom} /$ teaching stories, it is interesting to note that the Berlin wisdom model considers knowledge as the core of wisdom (Kunzmann \& Baltes, 2003). In this view, there are three main factors that contribute to the development of wisdom: (a) general personal attributes, such as intelligence and personality; (b) expertise-specific factors, such as experience with life problems, availability of mentors, and motivation; and (c) facilitative experiential contexts, such as age, parenthood, or work contexts (Baltes \& Staudinger, 2000). Hence, to a certain extent, internalized teaching stories could be seen as a parallel to the availability of mentors, and/or activate "Wise Mind".

There is no disputing the sociocultural importance of the image of wise individuals, such as Cleopatra or the Buddha (Bluck \& Gluck, 2004). However, in considering individuallevel personal identity, it is important to ascertain whether an individual has some sense of a self who is capable of wise thoughts and actions, and if so, how such a view of the self is embedded in his/her life story (Habermas \& Bluck, 2000). Importantly, even if this view of the self as a wise person does not appear as a trait-like semantic self-representation, it may contribute to one's identity formation through autobiographical memory. In the field of psychotherapy, it is widely accepted that wisdom "is an adaptive form of life judgment that involves not what but how one thinks. It refers to a combination of experiential knowledge, cognition, affect, and action that sometimes occurs in social context" (Bluck \& Gluck, 2004, p. 545). Consequently, wisdom is defined as a personal resource that is used to negotiate fundamental life changes and challenges, and is often directed toward the goals of living a good life or striving for the common good. Assuming that anyone can be wise given the right knowledge, right action (mindful application of knowledge), and/or through the right person-environmental fit, Bluck and Gluck (2004) applied a "wisdom of experience" procedure, which has been shown to be a valid means of studying experienced wisdom in everyday lives across the life span. By investigating narratives concerning times in which 
individuals said, thought, or did something wise, Bluck and Gluck (2004) showed that all age groups use experienced wisdom to transform negative life situations to positive ones; furthermore, they are equally likely to link these experienced wisdom events to larger temporal life periods. Young and older adults also relate wisdom experiences to their life stories by explaining how they are connected to later life consequences or to the direction that their lives had taken.

An important part of psychotherapy could be formulated as helping patients make sense of their life stories as they strive to take agency in them, understand them, learn from them, tell them to others, and relate them to others' stories. In MBT, the therapists facilitate such a process by actively using a case formulation in both group (Karterud, 2018) and individual therapies (Karterud et al., 2020). If the therapist has implemented a "key metaphor" (Bateman \& Fonagy, 2019, p. 257) in such a formulation, it may help the patient connect deeper with the content. Hence, the use of metaphors or teaching/wisdom stories may be an important element to consider in MBT, given the importance of working with one's personal narrative, narrative identity, and $\mathrm{a}(\mathrm{n}$ unconscious) route to access what is often denoted the perennial wisdom in ancient and current cultures.

\section{Cultural Bridges}

Another metaphorically-related aspect MBT could learn from DBT, is the implementation of cultural wisdom. As we have seen, therapeutic metaphors and/or stories can be rooted in the current situation. However, they can also describe patterns across situations in the patient's life, and/or reflect a deeper wisdom assimilated across culture and times. Hence, the use of metaphor allows for a more timeless communication. For instance, Wise Mind ("the inner wisdom that each person has") is a core concept in DBT (Linehan, 2014, p. 167). By pointing towards the collective wisdom, or "perennial philosophy" (Huxley, 2014), accumulated in various wisdom traditions (e.g., philosophical, scientific, spiritual, and/or religious), by what is typically denoted our inner teacher (Almaas, 2004), we can recognize a higher order of patterns, beyond lexical language (Singer \& Pope, 2012, p. 9). An alternative to tailored metaphors (e.g., selected from the patient's language and/or reflecting core patterns in the patient's life, and/or the therapeutic relation) is the cultural assimilation exemplified by the extensive use of teaching stories and metaphors from Zen Buddhism in DBT.

\section{A Fourth System of Epistemic Trust}

The act of telling stories, which tends to ignite our interest and imagination, may have the effect of making "dangerous" content more general (indirect validation); such an act can also make challenging interventions less confrontational in that, a "metaphor avoids direct confrontation and communicates ideas that may be unacceptable to clients at the conscious level" (Muran \& Digiuseppe, 1990, p. 75). For instance, addressing patients' eagerness to change quickly or their restlessness with others' slow progress could be playfully addressed by telling the following Zen story about a student who went to his teacher and said, "I have committed myself to your system. How long will it take me to succeed?" The teacher's response was, "Ten years." Impatiently, the student countered, "But if I work extremely hard, and do dedicate myself to practicing however many hours it takes each day, how long will mastery take then? The teacher though for a moment, and then replied "Twenty years" (de Vries, 2010, pp. xiii-xiv). Like skillful challenging (Rønnestad, 2016), another possible mechanism of using metaphors and teaching stories is as a means to develop an (unconscious) alliance (Davanloo, 1990) by creatively searching for and adapting metaphors of personal significance for the client, as this often can result in high persuasive impact and as such function as a forceful strategy for challenging dysfunctional thoughts and conceptions (Muran \& Digiuseppe, 1990, p. 79). We may argue that psychotherapists can "take their patients only as far as they themselves have come" (Karasu, 1999, p. 145). To help patients progress, Bateman et al. (2018) highlight three communication systems central for amending epistemic trust: (a) communication system 1: the teaching and learning of content; (b) communication system 2: the re-emergence of robust mentalizing; and (c) communication system 3: the re-emergence of social learning. Hence, to efficiently bypass individual idiosyncrasies, limitations of own understanding, and culture, the use of perennial wisdom contained in teaching stories or addressed by a metaphor, may restore a fourth system of epistemic trust-concerned with the collective wisdom of humanity at large. This phenomenon resembles what is denoted 'apta-vakya' ("trust in true knowledge from reliable sources") in Sanskrit (Picascia, 2019) or 'parrhesia' in Greek (Foucault, 1983).

In MBT, the individual therapy largely has the effect of preventing drop-outs (Andersen et al., 2021). Thus, having an alliance with the group and epistemic trust in other patients seem crucial elements for successful healing. Within wisdom research, Ardelt (2004) argued that wisdom goes beyond deep and complex knowledge and requires the transcendence of one's subjectivity and self-centeredness. Hence, the use of wisdom/teaching stories may be one way of introducing a greater understanding of experiences in a shared cultural context of social healing. Importantly, the therapeutic relationship should also enable each patient to develop other learning relationships, with an acquired sense of how to trust another person as a source of significant social information (Fonagy et al., 2019). This may be challenging to attain, as there are things that a person may be 
afraid to divulge even to him/herself, and every decent individual tends to have a number of such things stored away in their mind (Dostoevsky, 1999), e.g., individuals stand in their own shadow and wonder why it's dark (Zen proverb). Consequently, the use of metaphors, which simply put is to highlight similarities across differences (i.e., different individuals and/or situations), may facilitate such a process of exploration of "dangerous" topics through approaching the problem or situation within a different framework and thus potentially create new understanding. By learning a new language of expressing one's experience, the epistemic trust (restoring the ability for social learning) may develop by providing protection (layer of abstraction) from the vulnerability typically experienced in (group) therapy. Group cohesion is a core concept for understanding alliance in groups (Karterud et al., 2020). When the group can contain not only the particular patient's pain or problems, but also a generalized and/or more normative/culturally informed narrative, this may help the other patients relate to the topic. Such narratives also become part of the group field, which will translate the subjective experience into a larger map/mirror for all the participants. Hence, using metaphors in group therapy may help other patients relate deeper with the content. If a patient experiences that the other group members connect deeply with their core content (e.g., recognizes it, empathizes with it), it may not only be crucial for healing, but also what we denote alliance. This (working) alliance is a corrective experience, which may nurture Communication System 3-social learning from others. Promoting epistemic trust through metaphors, may provide a soothing effect of recognizing/understanding own painful patterns. As the use of metaphor is a way to abstract painful problems, and patterns, this may lead to the patient being less resistant towards corrective emotional experiences, both in- and outside therapy. If such social or relational development is experienced by the patient, this will likely foster further alliance (e.g., increased belief/trust in the presented healing myth, and the skills of the therapist) and accelerate potential healing.

\section{Metaphors Hold Great Potential when Responsively Applied}

As the potential harm of using metaphors has been identified (Muran \& Digiuseppe, 1990), the risk-reward ratio for metaphorical interventions could determine the division line between harm- and helpful therapy. Aristotle stated: "But the greatest thing by far is to be a master of metaphor. It is the one thing that cannot be learnt from others; and it is also a sign of genius, since a good metaphor implies an intuitive perception of the similarity in dissimilars" (Danto, 1993, p. 21). This may seem like a tough challenge. And it might not be for every therapist to include metaphors in their daily repertoire; one needs to have a certain interest or knack for the efficacious use of metaphor in the therapeutic relation. However, as any child can inform us, the inherent metalanguage of archetypical stories or fables may be able to somewhat transcend both the specific language barrier and the inherent idiosyncrasy of psychotherapy, if it is culturally and socially relevant, or at least applicable to their own life stories. In fact, throughout time and across cultures, people have made sense of their lives in story form (Bruner, 1990). However, despite Aristotle ascribing metaphors to genius, and stressing the importance of tailoring them, "it is widely accepted that linguistic competence entails a symmetrical capacity to form and to understand sentences, where no such symmetry is implied in metaphoring activities, in which you presumably do not have to be marked by genius to grasp metaphors once made. I suppose it must be roughly parallel to humor, in that making jokes is a gift of a certain order whereas getting jokes is ordinarily not" (Danto, 1993, p. 21). For some reason, certain stories become part of us, influencing how we view ourselves and the world. For example, there is a reason why we all remember that Alan Turing ended his life by taking a bite out of a poisoned apple. Typically, such images, stories, or metaphors make us understand a deeper reality or they tell us something about reality that is not easily understood. As imagery and metaphors are superior mnemonics (Lakoff \& Johnson, 2008), we would expect the use of metaphors in therapy to also increase memorability of new learnings. Contemplating this kind of resonance, George Eliot (i.e., Mary Anne Evans) thus preludes Chapter 31 of Middlemarch: "How will you know the pitch of that great bell/Too large for you to stir? Let but a flute/Play 'neath the fine-mixed metal listen close/Till the right note flows forth, a silvery rill:/Then shall the huge bell tremblethen the mass/With myriad waves concurrent shall respond/ In low soft unison" (Eliot, 2005, p. 568). Hence, Eliot may have indicated that, through resonance, we may grasp concepts beyond our normal reasoning, and the wonderful "lines telling of the great bell stirred by the note of a flute played at the proper pitch suggest the moving power that lies in sympathetic vibration. On a similar note, the first time a military body crossed the Brooklyn Bridge, the spectators were surprised to hear the order given for the soldiers to march out of step" (Miller, 2020, p. 34). While the resonance of such sympathetic vibration may have the effect of destroying a bridge, sympathetic vibrations may also be an essential part of human healing by collapsing cemented beliefs, or creating movement in subconscious material, e.g., through upheaving and changing familiar and unhealthy patterns of thought and behavior.

Expressing experiences or accumulated wisdom in the form of tailored metaphors in MBT may bridge our individual idiosyncrasies. Such resonance is often created by being personal, and it is almost paradoxical that clinical experience informs us that the more detailed and particular the emotions 
each patient dares to confront/explore/accept, the more others will recognize similar structures in themselves. Addressing the assumed universality at core of human experience, T.S. Eliot wrote that, "the business of the poet is not to find new emotions, but to use the ordinary ones" (Kermode \& Kermode, 1975, p. 43). Buddhist philosophy (Brown, 2006), as well as modern leadership theory, seem to indicate that general/universal principles may appear when investigating the inside of the individual: "Look, if this really is your 'one-big-thing,' if you've really dug deep enough, if you've really gotten personal, everybody already knows. I know. Others know. So, there's this sort of illusion out there that you are sharing something so private, that nobody knows. Trust me, they know!" (Kegan \& Lahey, 2009, p. 81). In terms of MBT, this may have two implications: First, the therapist needs not fear being too personal (though not private); second, there are universal principles, emotions, and archetypical patterns in the individual that can be transposed as wisdom from one person to another, especially in a healing relationship that fosters growth.

\section{Conclusion}

As research highlights the importance of the transmission of social knowledge in BPD treatments, it would be unwise to dismiss one of the biggest bites out of the fruit of the Tree of Knowledge that mankind has taken in recorded history: the invention of metaphors and stories (Harari, 2014). Metaphors may be an ostensive cue opening epistemic trust, and consequently also alliance. One typically finds that culturally embedded metaphors and teaching narratives are part of healing myths across time and space, and we see no reason why MBT therapists should not embody (and skillfully transmit) the wisdom contained in such traditions. However, the MBT therapist would also be advised to gain inspiration from the metaphors employed in other therapeutic approaches such as DBT and TFP.

Teaching stories and metaphors deserve more attention, as they could address the unconscious parts of patients' belief systems in different ways than what can easily be accomplished without such tools. Metaphors and stories may be shortcuts to implement new notions, viewpoints, and understandings. Telling a story in order to amend such maladaptive patterns "provides the conscious mind with one denotative message which keeps it occupied, while another therapeutic message can then be slipped to the unconscious mind via implication and connotation" (Muran \& Digiuseppe, 1990, p. 75). Stimulating the unconscious realms, like a child's fantasy world, may help grow new "mental tissue"-amending scars, replacing wrong notions. While writing may be the most timeless language possessed by mankind, our brains are still hardwired to learn through the ancient science of storytelling (Tomasello, 2010). Furthermore, teaching tales and metaphors are, in themselves, part of the culture. Hence, to the extent that evidence-based treatments can be considered a form of reeducation (Spinhoven et al., 2007), introducing patients to central concepts in culture, which are relevant to their current situation, seems logical: We do not need to reinvent the wheel, we just need to find new ways to use it.

Funding Open access funding provided by University of Oslo (incl Oslo University Hospital). The fourth author is funded by The Independent Research Fund Denmark (Grant No. 8023-00029B).

\section{Declarations}

Conflict of interest None of the above authors have any financial disclosure/conflict of interest related to this manuscript.

Informed Consent As this is a theoretical article, no informed consent was needed. No research on humans and/or animals was performed.

Open Access This article is licensed under a Creative Commons Attribution 4.0 International License, which permits use, sharing, adaptation, distribution and reproduction in any medium or format, as long as you give appropriate credit to the original author(s) and the source, provide a link to the Creative Commons licence, and indicate if changes were made. The images or other third party material in this article are included in the article's Creative Commons licence, unless indicated otherwise in a credit line to the material. If material is not included in the article's Creative Commons licence and your intended use is not permitted by statutory regulation or exceeds the permitted use, you will need to obtain permission directly from the copyright holder. To view a copy of this licence, visit http://creativecommons.org/licenses/by/4.0/.

\section{References}

Allen, J. G. (2012). Restoring mentalizing in attachment relationships: Treating trauma with plain old therapy. American Psychiatric Pub.

Almaas, A. (2004). The inner journey home: The soul's realization of the unity of reality. Shambhala Publications.

Andersen, C. F., Poulsen, S., Fog-Petersen, C., Jorgensen, M. S., \& Simonsen, E. (2021). Dropout from mentalization-based group treatment for adolescents with borderline personality features: A qualitative study. Psychotherapy Research, 31(5), 619-631. https://doi.org/10.1080/10503307.2020.1813914

Ardelt, M. (2004). Wisdom as expert knowledge system: A critical review of a contemporary operationalization of an ancient concept. Human Development, 47(5), 257-285.

Baltes, P. B., \& Staudinger, U. M. (2000). Wisdom. A metaheuristic (pragmatic) to orchestrate mind and virtue toward excellence. American Psychologist, 55(1), 122-136. https://doi.org/10.1037// 0003-066x.55.1.122

Bateman, A., Campbell, C., Luyten, P., \& Fonagy, P. (2018). A mentalization-based approach to common factors in the treatment of borderline personality disorder. Current Opinion in Psychology, 21, 44-49. https://doi.org/10.1016/j.copsyc.2017.09.005 
Bateman, A., \& Fonagy, P. (2016). Mentalization-based treatment for personality disorders: A practical guide. Oxford University Press.

Bateman, A. W., \& Fonagy, P. (2019). Handbook of mentalizing in mental health practice. American Psychiatric Pub.

Bluck, S., \& Gluck, J. (2004). Making things better and learning a lesson: Experiencing wisdom across the lifespan. Journal of Personality, 72(3), 543-572. https://doi.org/10.1111/j.0022-3506. 2004.00272.x

Bohnemeyer, J. (2020). Linguistic relativity: From Whorf to now. The Wiley Blackwell Companion to Semantics. https://doi.org/10.1002/ 9781118788516.sem013

Brown, D. P. (2006). Pointing out the great way: The stages of meditation in the Mahamudra tradition. Simon and Schuster.

Bruner, J. S. (1990). Acts of meaning (Vol. 3). Harvard University Press.

Clarkin, J. F., Yeomans, F. E., \& Kernberg, O. F. (1999). Psychotherapy for borderline personality. Wiley.

Croft, W., \& Cruse, D. A. (2004). Cognitive Linguistics. Cambridge University Press.

Danto, A. C. (1993). Metaphor and cognition. Knowledge and language (pp. 21-35). Springer.

Davanloo, H. (1990). Unlocking the unconscious. Wiley.

de Vries, M. F. K. (2010). Reflections on character and leadership: On the couch with Manfred Kets de Vries. Wiley.

Dostoevsky, F. (1999). Notes from the Underground, and The Gambler. OUP Oxford.

Eliot, G. (2005). Selected Novels of George Eliot. Wordsworth Editions. https://books.google.no/books?id=yhVOFqbpI18C

Folmo, E. J., Karterud, S. W., Kongerslev, M. T., Kvarstein, E. H., \& Stanicke, E. (2019). Battles of the comfort zone: Modelling therapeutic strategy, alliance, and epistemic trust-a qualitative study of mentalization-based therapy for borderline personality disorder. Journal of Contemporary Psychotherapy, 49(3), 141-151. https:// doi.org/10.1007/s10879-018-09414-3

Fonagy, P., Luyten, P., Allison, E., \& Campbell, C. (2019). Mentalizing, epistemic trust and the phenomenology of psychotherapy. Psychopathology, 52(2), 94-103. https://doi.org/10.1159/00050 1526

Foucault, M. (1983). Discourse and Truth-The Problematization of Parrhesia.

Glück, J., \& Bluck, S. (2013). The MORE life experience model: A theory of the development of personal wisdom. The scientific study of personal wisdom (pp. 75-97). Springer.

Goldfried, M. R. (1980). Toward the delineation of therapeutic change principles. American Psychologist, 35(11), 991-999. https://doi. org/10.1037//0003-066x.35.11.991

Habermas, T., \& Bluck, S. (2000). Getting a life: The emergence of the life story in adolescence. Psychological Bulletin, 126(5), 748-769. https://doi.org/10.1037/0033-2909.126.5.748

Hackmann, A., Bennett-Levy, J., \& Holmes, E. A. (2011). Oxford Guide to Imagery in Cognitive Therapy. OUP Oxford. https:// books.google.no/books?id=ngajYg3K8I8C

Harari, Y. N. (2014). Sapiens: A brief history of humankind. Random House.

Havsteen-Franklin, D. (2019). Mentalization-based creative arts therapies. In A. Bateman \& P. Fonagy (Eds.), Handbook of mentalizing in mental health practice. American Psychiatric Association Publishing.

Huxley, A. (2014). The perennial philosophy. McClelland \& Stewart.

Karasu, T. B. (1999). Spiritual psychotherapy. American Journal of Psychotherapy, 53(2), 143-162. https://doi.org/10.1176/appi. psychotherapy.1999.53.2.143

Karterud, S. (2018). Case formulations in mentalization-based group therapy. Res Psychother, 21(3), 318. https://doi.org/10.4081/ ripppo. 2018.318
Karterud, S., Folmo, E., \& Kongerslev, M. (2020). Mentaliseringsbasert terapi MBT. Gyldendal Akademisk.

Kegan, R., \& Lahey, L. L. (2009). Immunity to Change: How to Overcome it and Unlock Potential in Yourself and Your Organization. Harvard Business Press. https://books.google.no/books?id=rbhlT $\mathrm{Rx} 5$ VusC

Kermode, F., \& Kermode, J. F. (1975). Selected prose of TS Eliot. Faber.

Kohut, H. (1984). How does analysis cure Chicago. University of Chicago.

Kopp, R. R. (1995). Metaphor therapy: Using client-generated metaphors in psychotherapy. Psychology Press.

Kruglanski, A. W. (2013). Lay epistemics and human knowledge: Cognitive and motivational bases. Springer.

Kunzmann, U., \& Baltes, P. B. (2003). Beyond the traditional scope of intelligence: Wisdom in action. American Psychological Association.

Lakoff, G., \& Johnson, M. (2008). Metaphors we live by. University of Chicago press.

Leichsenring, F., Leibing, E., Kruse, J., New, A. S., \& Leweke, F. (2011). Borderline personality disorder. Lancet, 377(9759), 74-84. https://doi.org/10.1016/S0140-6736(10)61422-5

Lind, M., Thomsen, D. K., Boye, R., Heinskou, T., Simonsen, S., \& Jorgensen, C. R. (2019). Personal and parents' life stories in patients with borderline personality disorder. Scandinavian Journal of Psychology, 60(3), 231-242. https://doi.org/10.1111/sjop. 12529

Linehan, M. (2014). DBT? Guilford Publications.

Luyten, P., Campbell, C., Allison, E., \& Fonagy, P. (2020a). The Mentalizing Approach to Psychopathology: State of the Art and Future Directions. Annual Review of Clinical Psychology, 16, 297-325. https://doi.org/10.1146/annurev-clinpsy-071919-015355

Luyten, P., Campbell, C., \& Fonagy, P. (2020b). Borderline personality disorder, complex trauma, and problems with self and identity: A social-communicative approach. Journal of Personality, 88(1), 88-105. https://doi.org/10.1111/jopy.12483

McKeon, R. (2009). The Basic Works of Aristotle. Random House Publishing Group. https://books.google.no/books?id=EwT0y TR0y1MC

Miller, F. E. (2020). The Voice. Outlook Verlag. https://books.google. no/books?id=Y6r3DwAAQBAJ

Muran, J. C., \& Digiuseppe, R. A. (1990). Towards a cognitive formulation of metaphor use in psychotherapy. Clinical Psychology Review, 10(1), 69-85. https://doi.org/10.1016/0272-7358(90) 90107-L

Picascia, R. (2019). Defending the Authority of Scripture: Testimony as a Source of Knowledge in Classical Indian Philosophy of Religion [Doctoral dissertation, Harvard University, Graduate School of Arts \& Sciences]

Rønnestad, M. H. (2016). Is expertise in psychotherapy a useful construct. Psychotherapy Bulletin, 51(1), 11-13.

Sharp, C., Shohet, C., Givon, D., Penner, F., Marais, L., \& Fonagy, P. (2020). Learning to mentalize: A mediational approach for caregivers and therapists. Clinical Psychology-Science and Practice, 27(3), e12334. https://doi.org/10.1111/cpsp.12334

Singer, J. L., \& Pope, K. S. (2012). The power of human imagination: New methods in psychotherapy. Springer.

Spinhoven, P., Giesen-Bloo, J., van Dyck, R., Kooiman, K., \& Arntz, A. (2007). The therapeutic alliance in schema-focused therapy and transference-focused psychotherapy for borderline personality disorder. Journal of Consulting and Clinical Psychology, 75(1), 104-115. https://doi.org/10.1037/0022-006X.75.1.104

Tay, D. (2013). Metaphor in psychotherapy: A descriptive and prescriptive analysis (Vol. 1). John Benjamins Publishing. 
Tay, D. (2020). Affective engagement in metaphorical versus literal communication styles in counseling. Discourse Processes, 57(4), $360-375$.

Tomasello, M. (2010). Origins of human communication. MIT press. Wampold, B. E., \& Imel, Z. E. (2015). The great psychotherapy debate: The evidence for what makes psychotherapy work. Routledge.
Publisher's Note Springer Nature remains neutral with regard to jurisdictional claims in published maps and institutional affiliations. 